\title{
Development and multiplexing of microsatellite loci for the near threatened freshwater mussel Potomida littoralis (Cuvier, 1798) using 454 sequencing
}

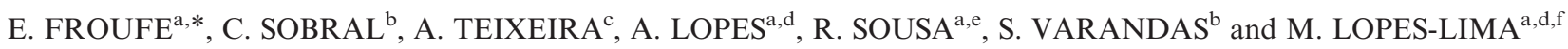 \\ ${ }^{a}$ Centre of Marine and Environmental Research, Porto, Portugal \\ ${ }^{\mathrm{b}}$ Forestry Department, Centre for Research and Technology of Agro-Environment and Biological Sciences, University of Trás-os-Montes \\ and Alto Douro, Vila Real, Portugal \\ ${ }^{\mathrm{c}}$ Mountain Research Centre, School of Agriculture, Polytechnic Institute of Bragança, Bragança, Portugal \\ ${ }^{\mathrm{d}}$ Institute of Biomedical Sciences Abel Salazar, University of Porto, Porto, Portugal \\ ${ }^{\mathrm{e}}$ Centre of Molecular and Environmental Biology, Department of Biology, University of Minho, Braga, Portugal \\ ${ }^{\mathrm{f}}$ Zoomarine, Albufeira, Portugal
}

\begin{abstract}
1. The Unionidae are among the most endangered fauna in the world and globally in decline. They are particularly vulnerable to habitat loss and fragmentation, susceptible to flow, pollution and climatic disturbances and introduction of invasive species. Despite their well-recognized ecological and conservation importance, there is a surprising lack of genomic resources currently available for European species.

2. The aim of this study was to develop and characterize microsatellites for the near threatened freshwater mussel, Potomida littoralis using 454 sequencing.

3. In order to improve genotyping throughput as well as cost-effectiveness, two multiplex-PCR reactions were designed to amplify 16 new loci. All the new 16 microsatellites were successfully combined in two multiplexed PCR with the number of alleles ranging from 2 to 25 per locus (with a mean of 10), confirming the utility of the new markers.

4. The new genetic markers can therefore be used for studying the population genetic structure and evolution of this species, e.g. to examine current levels of genetic variability within and between populations and thus to contribute to conservation and management.

Copyright (C) 2013 John Wiley \& Sons, Ltd.
\end{abstract}

Received 14 September 2012; Revised 29 November 2012; Accepted 06 January 2013

KEY WORDS: river; conservation evaluation; new techniques; genetics; invertebrates; molluscs

\section{INTRODUCTION}

Microsatellites or single sequence repeats (SSRs) are arrays of short repetitive motifs of 2-6 bp, that are distributed throughout the genome, co-dominantly expressed (Goldstein and Schlötterer, 1999). The number of times the unit is repeated in a given microsatellite can be highly variable, a characteristic that makes them one of the most common types of genetic markers. These markers are particularly suitable for studies at the population and individual levels (Duran et al., 2009) and are of great utility in conservation and management plans (Bouza et al., 2007; Geist et al., 2010a) since they are very effective for examining current levels of genetic

*Correspondence to: Elsa Froufe, Laboratory of Marine Community Ecology and Evolution, CIMAR-LA/CIIMAR-UP Centre of Marine and Environmental Research, Rua dos Bragas 289, 4050-123 Porto, Portugal. E-mail: elsafroufe@gmail.com 
variability within and between populations. Genetic variability is important for population persistence, especially in species that have become fragmented or bottlenecked. The distribution of microsatellite allele frequencies can be used as analytical tools in identifying populations that have suffered recent bottlenecks, making it possible to quantify the severity of the size reduction, and by allowing the assessment of effective population size, inbreeding, and migration (Allendorf and Luikart, 2007). Traditional cloning methods of developing microsatellites involve significant trial and error (Queller et al., 1993), are very time consuming and as a result can be cost-prohibitive. Recent advances in sequencing technology, such as 454 (Roche), designed for whole-genome sequencing, are valuable and cost-effective means of searching for microsatellites on non-model organisms. This new sequencing scheme represents a significant gain in time and cost, by producing millions of base pairs of short fragment reads, which may be screened using bioinformatics toolsets to identify primers that amplify polymorphic microsatellite loci (Duran et al., 2009).

The aim of this study was to develop and characterize microsatellites for the near threatened (Cuttelod et al., 2011) freshwater mussel, Potomida littoralis (Cuvier, 1798), (Bivalvia: Unionoida). This species occurs in a patchy circum-Mediterranean distribution, from Portugal to France, Greece, Middle East (Turkey and Syria) and Northern Africa. On the other hand, the species has been declining in recent decades in all Iberian Peninsula populations (Pérez-Quintero, 2007; Barea-Azcón et al., 2008) and should be considered for full protection by the European Habitats Directive (Bouchet et al., 1999). The Unionidae (Mollusca) are among the most endangered fauna in the world and globally in decline (Lydeard et al., 2004). They are particularly vulnerable to habitat loss and fragmentation, susceptible to flow, pollution and climatic disturbances and introduction of invasive species (Strayer et al., 2004). Moreover, and despite their well-recognized ecological importance, there is a surprising lack of genomic resources currently available for European species (Skidmore et al., 2010). To the best of our knowledge, existing microsatellite primers are only available for two of the native European unionoids A. cygnea (Geist et al., 2010b) and M. margaritifera (Geist et al., 2003). The knowledge and measurement of genetic variation within and among populations is important for many unionoid species (Bogan and Roe, 2008). Thus questions about population structure, effective population size, the impact of habitat modification, reproductive ecology and contemporary phylogeography (which still remain virtually unknown for the majority of European unionoid species) will greatly benefit from the availability of microsatellites isolated using modern pyrosequencing of enriched DNA libraries. Such research can in turn be used in developing future conservation strategies designed to maintain the variability of the species, essential for its evolution and survival, by identifying conservation units, i.e., evolutionary significant units and management units.

\section{METHODS}

A small tissue sample from the foot of 75 P. littoralis was collected (following Naimo et al., 1998) from three distinct populations, each corresponding to three major Iberian river basins: Douro, Tejo and Guadiana. Total genomic DNA was extracted from a single individual using a standard high-salt protocol (Sambrook et al., 1989) and sent to Genoscreen (Lille, France) for microsatellite-enriched library preparation and sequencing by 454 Genome Sequencer FLX Titanium (454, Roche Applied Science) using the method described in Malausa et al. (2011) The sequences were received as multiple fasta files with the corresponding quality files.

To improve genotyping throughput as well as cost-effectiveness, two multiplex-PCR reactions were designed to amplify the new loci. Multiplexing consists of the amplification of several markers in a single PCR and can, therefore, significantly improve genotyping throughput as well as cost-effectiveness. For the first choice of loci to take on to further testing, two sets of 10 primers pairs each were chosen, taking into account several criteria such as the size of the resulting amplicons (small and large loci to maximize their capillary separation), the different motif classes (the three perfect motifs were chosen with simple repeats only) and, evidently, the compatibility of the primers from the different loci for PCR multiplexing.

A GTTT-sequence 'pig-tail' tag was added to the 5 ' end of all reverse primers (reduces stutter bands; Brownstein et al., 1996) and a combination of the NED, VIC, PET, or 6FAM (Applied Biosystems, CA) dyes to the forward primers according to the multiplex essay (Table 1). Allelic variation was initially tested on nine individuals (three per 
MULTIPLEXING MICROSATELLITES FOR POTOMIDA LITTORALIS

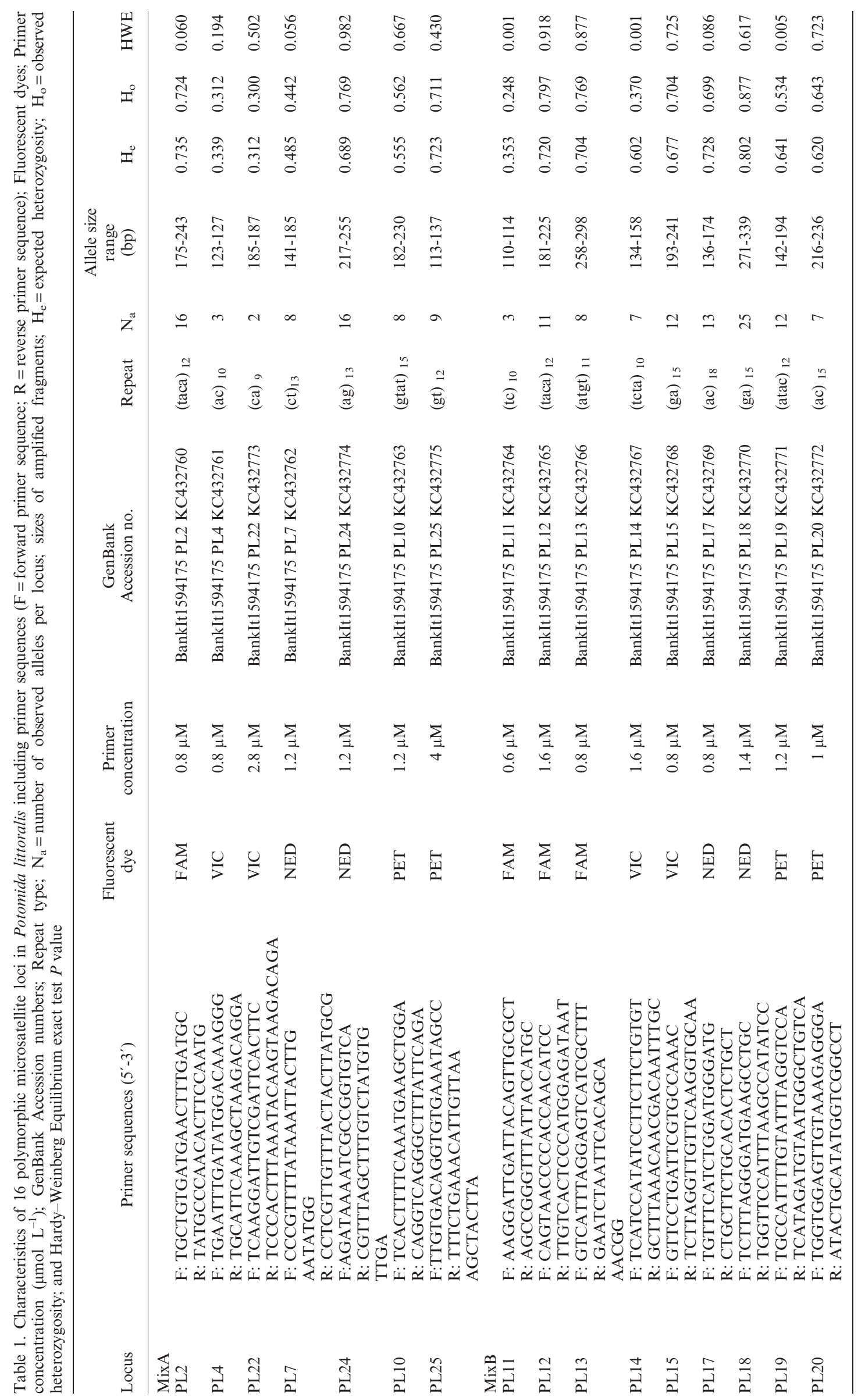


population) with PCR reactions in simplex to validate selected loci and ascertain optimal annealing temperatures. After this trial, 16 loci were selected, combined in two multiplex-PCR reactions (seven in MixA and nine in MixB) and tested for polymorphism in all the 75 individuals. PCR amplifications were performed in $10 \mu \mathrm{L}$ reactions containing $1 \mu \mathrm{L}$ of $25 \mathrm{ng}$ of template DNA, $5 \mu \mathrm{L}$ of Qiagen multiplex PCR mastermix, $1 \mu \mathrm{L}$ of primer-mix (variable concentrations of primer pairs and fluorescent dyes according to prior optimization of multiplex reactions; see Table 1) and $3 \mu \mathrm{L}$ of $\mathrm{H}_{2} \mathrm{O}$. PCR reactions were performed on a DNA Engine Dyad ${ }^{\circledR}$ Peltier Thermal Cycler (Bio-Rad Laboratories), consisting of a denaturing step at $95^{\circ} \mathrm{C}$ for $15 \mathrm{~min}$ followed by 11 cycles of denaturation at $95^{\circ} \mathrm{C}$ for $30 \mathrm{~s}, 60 \mathrm{~s}$ annealing at $60^{\circ} \mathrm{C}$ where the annealing temperature was lowered by $0.5^{\circ} \mathrm{C}$ with each consecutive cycle, and $30 \mathrm{~s}$ elongation at $72^{\circ} \mathrm{C}$; 21 cycles of denaturation at $95^{\circ} \mathrm{C}$ for $30 \mathrm{~s}$, annealing at $55^{\circ} \mathrm{C}$ for $45 \mathrm{~s}$, and extension at $72^{\circ} \mathrm{C}$ for $30 \mathrm{~s}$; eight cycles at $95^{\circ} \mathrm{C}$ for $30 \mathrm{~s}, 53^{\circ} \mathrm{C}$ for $30 \mathrm{~s}, 72^{\circ} \mathrm{C}$ for $30 \mathrm{~s}$, and a final extension at $60^{\circ} \mathrm{C}$ for $30 \mathrm{~min}$. Labelled PCR amplicons were resuspended in $10 \mu \mathrm{L} \mathrm{Hi-Di}{ }^{\mathrm{TM}}$ Formamide and their sizes determined in an Applied Biosystems 3100 DNA analyser, with LIZ 500 size standard as an internal size standard.

Alleles were scored using GeneMapper ${ }^{\circledR}$ v 4.0 (Applied Biosystems). GENEPOP v 4.0 (Raymond and Rousset, 1995) and Arlequin v 3.5.1.2 (Excoffier and Lischer, 2010) were used to estimate diversities and expected and observed heterozygosities $\left(\mathrm{H}_{\mathrm{e}}\right.$ and $\mathrm{H}_{\mathrm{o}}$, respectively) and to test Hardy-Weinberg equilibrium (HWE).

\section{RESULTS}

Of the 12561 reads obtained, 3566 contained microsatellite inserts, of which 1558 contained microsatellite inserts with perfect motifs (only one motif) and simple repeats only, from di- to tetranucleotide, suitable for primer design. The amplicon sizes varied from $90 \mathrm{bp}$ to $320 \mathrm{bp}$. Of these, $58.4 \%$ were dinucleotides, $20.0 \%$ trinucleotides and $21.6 \%$ tetranucleotides. GA and AC repeats were the most common dinucleotide repeats, TTG and ACA the most common trinucleotide repeats, and GTAT and CATA the most common tetranucleotide repeats.

All 16 loci were successfully combined in two multiplexed PCRs (Table 1) and yielded very clear and balanced electrophoresis profiles that matched the peaks obtained from single-locus PCRs.
Number of alleles ranged from 2 to 25 per locus with a mean of 10 (Table 1). $\mathrm{H}_{\mathrm{e}}$ and $\mathrm{H}_{\mathrm{o}}$ as well as the $P$ values for the Hardy-Weinberg Equilibrium are also shown in Table 1.

\section{DISCUSSION}

Overall, this study shows the usefulness of second-generation sequencing of microsatellite-enriched library to develop new microsatellites in non-model organisms in a shorter time and at relatively low expense compared with traditional methods. In addition, the strategy used here, i.e. the amplification of several markers in a single PCR, significantly improved genotyping throughput as well as cost-effectiveness. This technique is still underused when scoring microsatellites, and given the excellent results shown in this study it appears promising for future and wider applications in conservation genetics.

The new 16 loci characterized here confirm their utility and great potential for fine-scale geographic studies in $P$. littoralis, since there are several and they are polymorphic. Microsatellites are good indicators of genetic diversity, measuring between-population connectivity at a scale equal to or smaller than the dispersal range of the species under study (Allendorf and Luikart, 2007). They can also allow the identification of bottlenecked populations, consequently holding promise for effective conservation measures for this species (Allendorf and Luikart, 2007). By examining the current levels of genetic variability within and between populations, and thus improving the understanding of this species' life history, they can be used in future conservation management actions (Geist et al., 2010a).

Preventing the extinction of populations is a basic goal in conservation, and maintaining genetic diversity will tend to reduce the probability of extinction. Besides identifying populations that have suffered recent bottlenecks, analytical tests using the microsatellite results can help quantify the severity of the size reduction (Luikart et al., 1998). Therefore, even before a substantial loss of genetic variability occurs, a population might have a bottleneck signature that is detectable using microsatellites in bottleneck detection tests (Piry et al., 1999). Genetic considerations are probably most useful when incorporated early in a species' conservation plan, when the existence of some robust populations across a species' geographical 
range offers the possibility of a variety of creative solutions to conservation problems (Hedrick, 2001). Many native European unionoid species have suffered serious declines but are not yet exposed to an imminent risk of extinction, rendering molecular studies particularly timely. Freshwater mussels depend on aquatic habitats, and for protection and management plans their local population dynamics as well as the degree of population connectivity must be considered. Microsatellites are particularly suitable for inferring recent population history and contemporary gene flow between fragmented subpopulations. These new markers may also be tested and used for related species.

\section{ACKNOWLEDGEMENTS}

The authors wish to thank the two anonymous reviewers and Phil Boon for helpful remarks and suggestions that improved the quality of the manuscript. Financial support was provided by Portuguese Foundation for Science and Technology (FCT) project PTDC/AAC-AMB/117688/2010. We would like to thank Susana Lopes for help with fragment analysis and acknowledge the assistance of staff at Genoscreen for generation of 454 sequence reads and DNA Sequencing.

\section{REFERENCES}

Allendorf FW, Luikart G. 2007. Conservation and the Genetics of Populations. Blackwell: Malden, MA.

Barea-Azcón JM, Ballesteros-Duperón E, Moreno D. 2008. Libro Rojo de los Invertebrados de Andalucía. Consejería de Medio Ambiente, Junta de Andalucía: Sevilla.

Bogan AE, Roe KJ. 2008. Freshwater bivalve (Unioniformes) diversity, systematics, and evolution: status and future directions. Journal of the North American Benthological Society 27: 349-369.

Bouchet P, Falkner G, Seddon MB. 1999. List of protected land and freshwater molluscs in the Bern convention and European Habitats Directive: are they relevant to conservation? Biological Conservation 90: 21-31.

Bouza C, Castro J, Martínez P, Amaro R, Fernández C, Ondina P, Outeiro A, San Miguel E. 2007. Threatened freshwater pearl mussel Margaritifera margaritifera $\mathrm{L}$. in NW Spain: low and very structured genetic variation in southern peripheral populations assessed using microsatellite markers. Conservation Genetics 8: 937-948.

Brownstein MJ, Carpten JD, Smith JR. 1996. Modulation of non-templated nucleotide addition by Taq DNA polymerase: primer modifications that facilitate genotyping. Biotechniques 20: 1004-1010.

Cuttelod A, Seddon M, Neubert E. 2011. European Red List of Non-marine Molluscs. Publications Office of the European Union: Luxembourg.
Duran C, Appleby N, Edwards D, Batley J. 2009. Molecular genetic markers: discovery, applications, data storage and visualisation. Current Bioinformatics 4: 16-27.

Excoffier L, Lischer HEL. 2010. Arlequin suite ver 3.5: a new series of programs to perform population genetics analyses under Linux and Windows. Molecular Ecology Resources 10: 564-567.

Geist J, Rottmann O, Schröder W, Kühn R. 2003. Development of microsatellite markers for the endangered freshwater pearl mussel Margaritifera margaritifera L. (Bivalvia: Unionoidea). Molecular Ecology Notes 3: 444446.

Geist J, Söderberg H, Karlberg A, Kuehn R. 2010a. Drainage-independent genetic structure and high genetic diversity of endangered freshwater pearl mussels (Margaritifera margaritifera) in northern Europe. Conservation Genetics 11: 1339-1350.

Geist J, Geismar J, Kuehn R. 2010b. Isolation and characterization of the first microsatellite markers for the endangered swan mussel Anodonta cygnea L. (Bivalvia: Unionoidea). Conservation Genetics 11: 1103-1106.

Goldstein DB, Schlötterer C. 1999. Microsatellites Evolution and Applications. Oxford University Press: New York.

Hedrick PW. 2001. Conservation genetics: where are we now? Trends in Ecology \& Evolution 16: 629-636.

Luikart G, Allendorf FW, Cornuet JM, Sherwin WB. 1998. Distortion of allele frequency distributions provides a test for recent population bottlenecks. Journal of Heredity 89: 238-247.

Lydeard C, Cowie RH, Bogan AE, Bouchet P, Cummings KS, Frest TJ, Herbert DG, Hershler R, Gargominy O, Perez K, et al. 2004. The global decline of nonmarine mollusks. BioScience 54: 321-330.

Malausa T, Gilles A, Meglécz E, Blanquart H, Duthoy S, Costedoat C, Dubut V, Pech N, Castagnone-Sereno P, Délye C, et al. 2011. High-throughput microsatellite isolation through 454 GS-FLX titanium pyrosequencing of enriched DNA libraries. Molecular Ecology Resources 11: 638-644.

Naimo TJ, Damschen ED, Rada RG, Monroe EM. 1998. Nonlethal evaluation of the physiological health of unionid mussels: methods for biopsy and glycogen analysis: Journal of the North American Benthological Society 17: 121-128.

Pérez-Quintero JC. 2007. Diversity, habitat use and conservation of freshwater molluscs in the lower Guadiana River basin (SW Iberian Peninsula). Aquatic Conservation: Marine and Freshwater Ecosystems 17: 485-501.

Piry S, Luikart G, Cornuet JM. 1999. BOTTLENECK: a computer program for detecting recent reductions in the effective population size using allele frequency data. Journal of Heredity 90: 502-503.

Queller DC, Strassman JE, Hughes CR. 1993. Microsatellites and kinship. Trends in Ecology \& Evolution 8: 285-288.

Raymond M, Rousset F .1995. GENEPOP - population genetics software for exact tests and ecumenicism. Journal of Heredity 86: 248-249.

Sambrook J, Fritsch EF, Maniatis T. 1989. Molecular Cloning: A Laboratory Manual. Cold Harbor Spring Press: New York.

Skidmore R, Leach C, Hoffman J, Amos W, Aldridge DC. 2010. Conservation genetics of the endangered depressed river mussels, Pseudanodonta complanata, using amplified fragment length polymorphism (AFLP) markers. Aquatic Conservation: Marine and Freshwater Ecosystems 20: 560-567.

Strayer DL, Downing JA, Haag WR, King TL, Layzer JB, Newton TJ, Nichols SJ. 2004. Changing perspectives on pearly mussels, North America's most imperilled animals. BioScience 54: 429-439. 